\title{
Design and Analysis of a Double-well Mutual Balance Hydraulic Pumping Unit
}

\author{
Gong-xiang Zhong ${ }^{1}$, Xiao-hua $\mathrm{Li}^{2}$, Lin Jing ${ }^{3}$ \\ (Education Ministry Key Laboratory of Oil and Gas Equipment, Southwest Petroleum University, Chengdu 610500)
}

\begin{abstract}
According to the characteristics of the small spacing of cluster wells, this paper designs a double-well mutual balance hydraulic pumping unit. One pumping unit is used for two wells, and it achieves interactive balancepumpingthrough two balanced hydraulic cylinders. The hydraulic system is simulated by AMESim software. The simulation results are in good agreement with the design curve, which proves the designed pumping unit has excellent working performance.
\end{abstract}

Keywords: double wells; hydraulic system design; AMESim analysis; system simulation; hydraulic components

\section{Introduction}

From the point of view of the develop-ment process of pumping, pumpingthegene-ral trend of technological development towards long stroke, large load, precisionbalance, save energy, adaptabilityand otherasp-ects of development.Hydraulicfluid is ess-ential for modern industrial energyintensi-ve transmission mode, it can minimizetheequipment size and weight. The hydraulic pumping unit character is use for hydraulicdrivetechnology, which can maximize wellproductivity, good oil economy, especially for the late development of hydraulic pum-ping heavy oil and oil fields aremoreatta-rctive[1].Formation of products at home andabroad and in the development stage of h-ydraulic pumping unit are mostly adopts s-ingle well oil production method, using theaccumulator as well as the applied load tobalance the well up and down stroke.Sin-glewell oil hydraulic pumping unit has be-en well used in foreign countries, and ach-ieved the expected results.But for the li-mited space, the number of multiwelloil field, the oil well a hydraulic pumping w-ork must result in equipment footprint, hi-gh equipment purchasecost, low energy ef-ficiency.To solve this problem, thispropo-se put forwarda double-well mutual bala-ncehydraulic pumping unit with a hydrau-lic pumping unit while pumping wells, wi-th better economic benefits. Two differenti-al oil pump work, it use of two wells up and downstroke difference balanceng.By adjusting the depth, sucker rod pump com-binations and pump diameter size at two wells pump, so that the load balance eachother twowells can be made more precisebalancingand energy efficiency.

\section{Hydraulic pumping unit of hydraulic s-ystem design}

Thedouble-well mutual balance hydraul-icpumping unit hydraulic system is mainycomposed of the power unit, control valve-s, actuators, hydraulic accessories and hyd-raulic medium of five parts, the basic stru-cture shown in Figure 1.Power means forthe two variable piston pump as the main pump system (3-1, 3-2), is provided at theaccumulatorcharge pump (3-4), in additionto the system set a manual pump (8); Themainof pressure control valve haspilotrel-ief valve (5-1, 5-2) and directacting r-eliefvalve (11); themain of flow control val-vehas flow diversion valve (10-1, 10-2, $10-3,10-4,10-5,10-6)$; the main of directional.

1. Tank; 2 suction filter; 3 hydraulic pump; 4 motor; 5 . Pilot Relief Valve (with relief); 6-way valve; 7 electro-hydraulic valve; 8 manually change 9 manual shut-off valve; the valve 10 bypass flow valve; 11 directly Operated; 12 pressure switch; 13 cooler; 14 gauge; 15 drive the hydraulic cylinder; hydraulic balance 16 . cylinder; 17 accumulator; 18 heater;. SQ limit switch;. A, B, C, D, E, F quick connector.

Figure 1 Double-well Mutual Balance Hydraulic Pumping Unit hydraulic system diagram

Control valve with a check valve (6-1, 6-2, 6-3, 6-4), electrohydraulic valve 7 , manual valve 8 ; actuator consists of balancing hy-draulic cylinders $(16-1,16-2)$ and a drive cylinder (15-1, 15-2).Hydraulic accessores-including tank (1), fittings, filters(2), a he-at exchanger $(13,18)$, the accumulator (17), indicating instrument (14), pressure sw-itch (12), limit switch (SQ), etc; hydraulicmedium HM antiwear hydraulic oil.Accor-ding to the flow rate is determined by sp-eed, the velocity of driving hydraulic cyli-nder will direct result ofthe large flow ofsystem is needed, pumping unit strokereq-uire adjust, it demand of the system provi-ded by adjustable flow range is adjustable.So choose two adjustable quantitative pist-on pump as the main pump system (3-1, 3-2), The system required flow is large, o-pen two hydraulic pumps at the same time, the system needed to little flow, it regulatethe hydraulic pump of variable institution or only open a pump.The accumulator is provided at a charge pump (3-4), it useofsupplement pressure oil for the accumulat-or for the first time to use, when the bal-ance cylinder system leaks to supplement oil for its pipeline.In addition the system setup manual pump (8), is used in the ca-se of the main system is not work, it gua-ranteeddriving the hydrauliccylinder posi-tion.Two flow diversion valve are comm-unicated with a balanced hydraulic cylinde-rs (16-1, 16-2) in the front chamber and the other balancing hydraulic cylinders $(1-6-1,16-2)$ of the rear chamber.Flow dive-rsion 


\section{International Journal of Science and Research (IJSR) \\ ISSN (Online): 2319-7064 \\ Index Copernicus Value (2013): 6.14 | Impact Factor (2015): 6.391}

valve on the oil supply system will be $1: 1$ split, the pressure of the hydraulic oil comes from the power source score di-vided into two parts, transported to the ba-lancing hydraulic cylinders to achieve drive the two hydraulic cylinders synchronous phase operation.

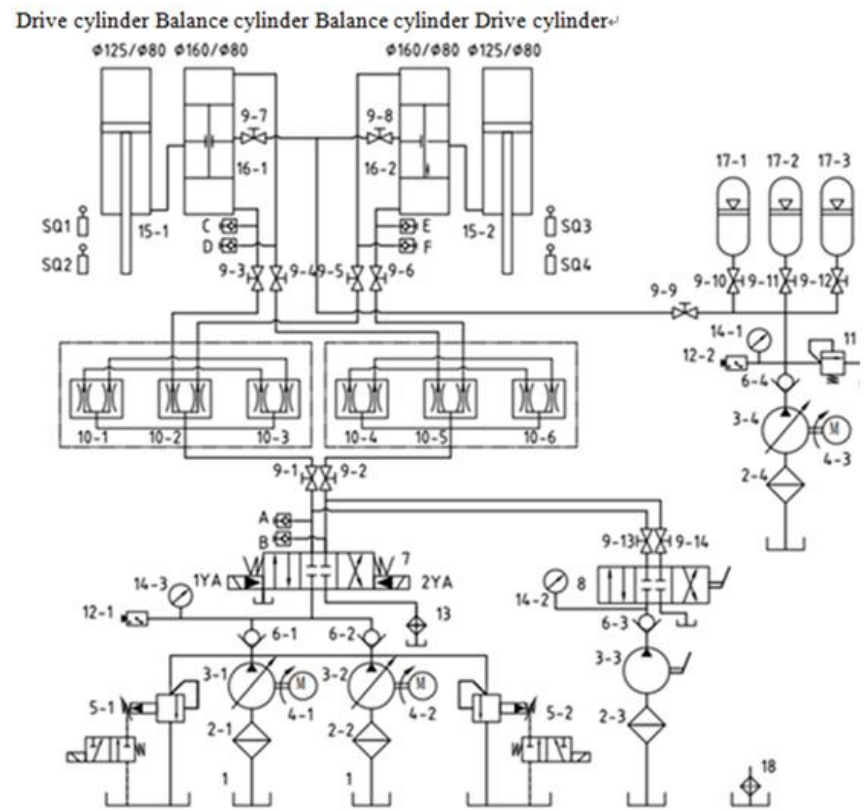

\section{Hydraulic System Works Analysis}

Double-well mutual balance hydraulic p-umping unit is mainly used in the oil do-uble-well conditions, but also have a singl-ewell oil production capabilities. When onewell needs workover or encounter other i-mmeasurably factors cannot be recoveryoilin a short time, it can take advantage of features of single well oil. When thedouble-well work, each element work con-ditionof the hydraulic system as follows:

\subsection{Analysis of the principle double-well}

Limit switch SQ1, SQ2 detected piston-stroke of thedrivinghydraulic cylinder 1-5-1, limit switch SQ1 is located at the topdead center, limit switch SQ2 is located atthe down dead center of the pistonstroke. When the drive cylinder 15-1piston rod islocated in the lower dead point, the limit switch SQ2 receive electrical signals appli-ed to the electro-hydraulic valve 7 , so thatthe electro-hydraulic valve 1 YA was electr-ic, electro-hydraulic valve fluid communic-ation with the left.At this time, the pow-er plant sent out from the highpressure f-luid through the check valve6-1 and 6-2 to reach the left side of the electrohydrau-lic valve 7;hydraulic oil conveyed by theelectro-hydraulic valve in the bypasssflowvalve $10-1,10-2,10-3$ is at $1: 1$ split, the s-plit oilrespectively reach balance cylinder 16-1 lower chamber and 16-2 up chamber.Balancing hydraulic cylinders 16-1 oil pre-ssure chamber pressure is increased to pro-mote the drive cylinder $15-1$ on the trip. Balance hydraulic cylinder 16-2 up chamb-erpressure oil and drive hydraulic cylinder15-2 load both to promote balance hydrau-lic cylinders 16-2 oil return, thus promote-ng driving the hydraulic cylinders 15-2 do-wn stroke. Balancing hydraulic cylinders 1-6-1 oil return through the upper chamber and flow diversion valve $10-4,10-5,10-6$ b-ack to the tank.Its passage schematic dia-gram shown in Figure 2

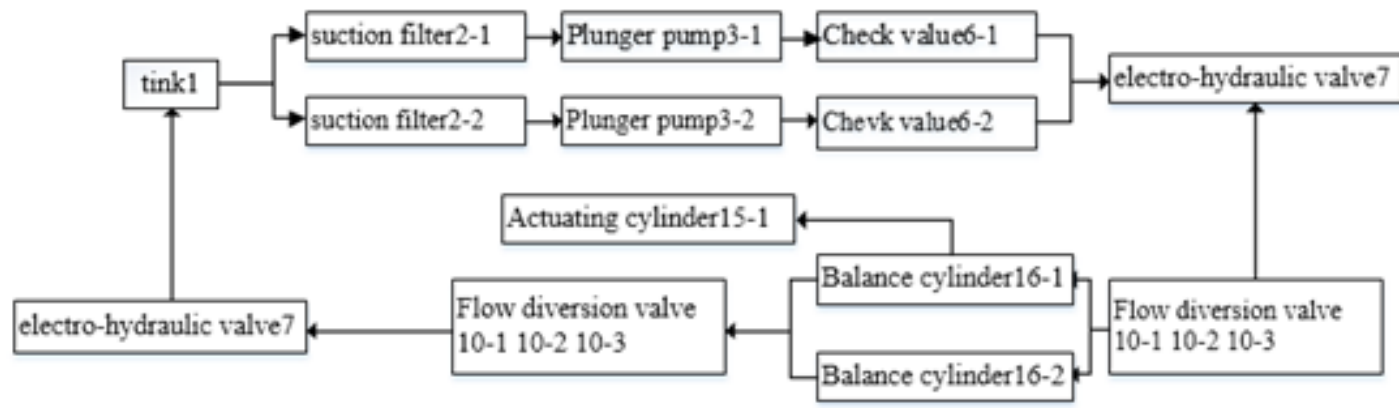

Figure 2: shuangjing working oil flow schematic

When the drive cylinder $15-1$ piston ro-d is located in the top dead center, the tr-ip switch SQ1 receive electrical signals a-pplied to the electro-hydraulicvalve 7 , so that the electro-hydraulic valve 2YA was electric, electro-hydraulicvalve the right ofcommunication with the fluid.

\subsection{Analysis of the principle of single well}

Whenasingle well work, driving the hydraulic cylinders $15-1$ or $15-2$ drive the hydraulic cylinders working separately, each element in the work of this particular analysis of the hydraulic cylinder drive system 15-1 work alone. Closemanual shut-off valve 9-1, 9-2, 9-3, 9-4 and 9-8, with hydraulic hoses and qui-ck connectors A C, B and D. Limit

Volume 5 Issue 6, June 2016 www.ijsr.net 


\section{International Journal of Science and Research (IJSR) \\ ISSN (Online): 2319-7064 \\ Index Copernicus Value (2013): 6.14 | Impact Factor (2015): 6.391}

switch SQ1 and SQ2 limit switch detecting dri-ver hydraulic cylinder 15-1 piston stroke, limit switch SQ1 15-1 is located at the t-op dead center of the piston stroke, limit switch SQ1 $15-2$ is located at the under dead center of the piston stroke.

When the drive cylinder $15-1$ piston ro-d is located in the lower dead point, the limit switch SQ2 receive electrical signals applied to the electro-hydraulic valve 7, sothat the electro-hydraulic valve 1YA was electric, electro-hydraulic valve fluid com-munication with the left side of the drivecylinder 15-1 start on the stroke movement.Its passage schematic diagram shown in Figure 3.

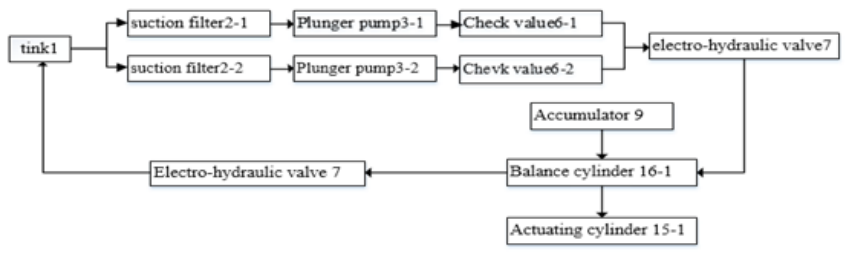

Figure 3: a schematic view of a single well working oil flow

When the drive cylinder $15-1$ piston ro-d is located in the top dead center, the tr-ip switch SQ1 receive electrical signals a-pplied to the electro-hydraulic valve 7 , so that the electro-hydraulic valve 2YA was electric, electro-hydraulic valve the right ofcommunication with the fluid driven cylin-der 15-1 to start the next stroke moveme-nt.

\section{Pumping Operation Curve Planning}

According to the relevant technical para-meters of the existing hydraulic pumping unit is designed to determine the pumping-stroke of $6 \mathrm{~m}$, pumping 4 times. The actualsituation, the pumping speed curve is usu-ally designed into sinusoidal and trapezoidalprofile.Sinusoidal velocity curve used f-or beam pumping unit, trapezoidal velocitycurve used for the new multi-linear oil pr-oduction equipment, which motion process comprises uniformly accelerated, uniform, uniform deceleration phase and the inverte-d repeat this procedure.According to stro-ke, stroke frequency, accelerationandspeedrequirements, design of hydraulic pumpingunit suspension point velocity trapezoidal speed profile ${ }^{[4]}$, as shown in Figure 4. t1- acceleration time, deceleration time; t2- uniform time.

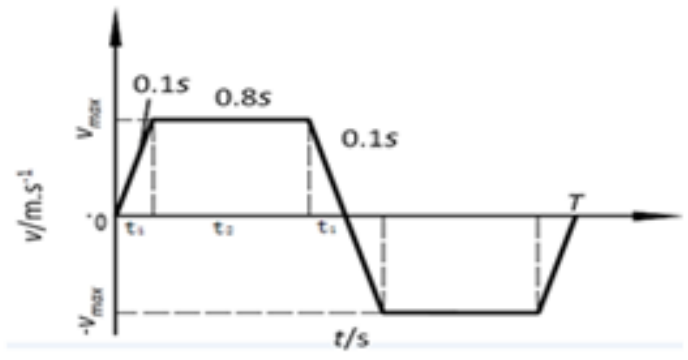

Figure 4: trapezoidal velocity curve design

Within a cycle of run light pole run $12 \mathrm{~m}$, where the up stroke $6 \mathrm{~m}$, the lower str-oke $6 \mathrm{~m}$.Early light rod running from the bottom dead center begins to move, aftertime $t$, $0.6 \mathrm{~m}$ of uniformly accelerated the campaign began uniform motion, after uniform motion time $\mathrm{t} 2,4.8 \mathrm{~m}$ started deca-leration, deceleration time is $\mathrm{t} 1$, decelerate-on distance is $0.6 \mathrm{~m}$.According to Figure 4 lists the following formula.

$$
\begin{gathered}
2 t_{1}+t_{2}=7.5 \\
a t_{1} t_{2}=4.8 \\
\frac{1}{2} a t_{1}^{2}=0.6
\end{gathered}
$$

United the formula (1), (2), (3), calculatedvalue of the acceleration during accelerate-on and deceleration of $0.768 \mathrm{~m} / \mathrm{s}^{2}$; maxim-um operating speed of the rod is $0.96 \mathrm{~m} / \mathrm{s}$.

\section{Hydraulic system AMESimsimulation}

It was established driven hydraulic cyli-nders and load model, balancing hydraulic cylinders model, flow diversion valve mod-el in AMESim ${ }^{[3,4]}$.Combining element mo-dule and modeling analysis of some of th-e components, the establishment ofdouble-wellmutual balance double-well oil hydra-ulic pumping unit of AMESim model, a model shown in Figure 5, for the entire h-ydraulic system simulation.

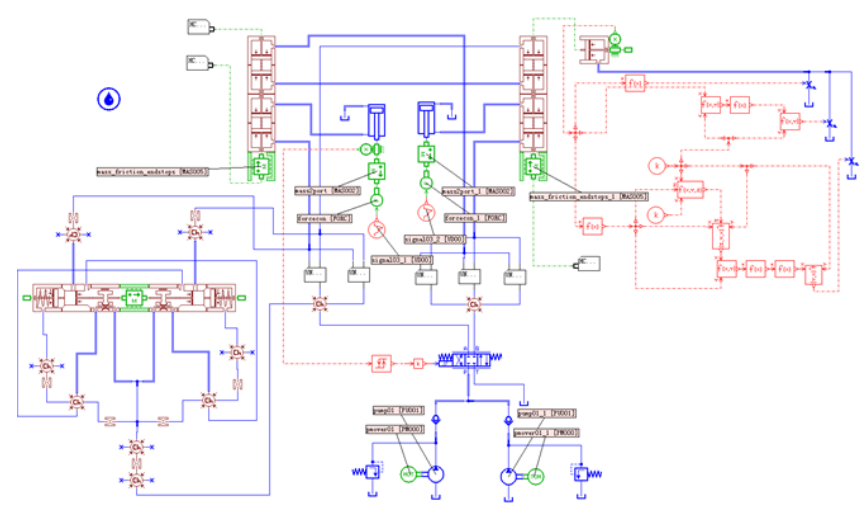

Figure 5: Shua-ngjing mutual balance Shuangjing oil hydraulic pumping unit of AMESim model

Setting hydraulic pump 01, pump 01_1 displacement of $282 \mathrm{ml} / \mathrm{r}$, motor pmover01, pmover01_1 rotational speed of $1480 \mathrm{r} / \mathrm{min}$, in two stagesanalogload signalsignal03_1, signal03_2 of signal value, namely the up stroke $160 \mathrm{kN}$ and lower stroke stroke $65 \mathrm{kN}$.Setting simulation time is 60seconds, graphic printing interval of 1 seconds, for thedouble-well mutual balance double-well oil hydraulic pumping unit of AMESim modelsimulation.

The results of simulation after processing by driving hydraulic cylinder 1 load curve as shown in figure 6 , the displacement curve as shown in figure 7 , speed curve as shown in figure 8 . 


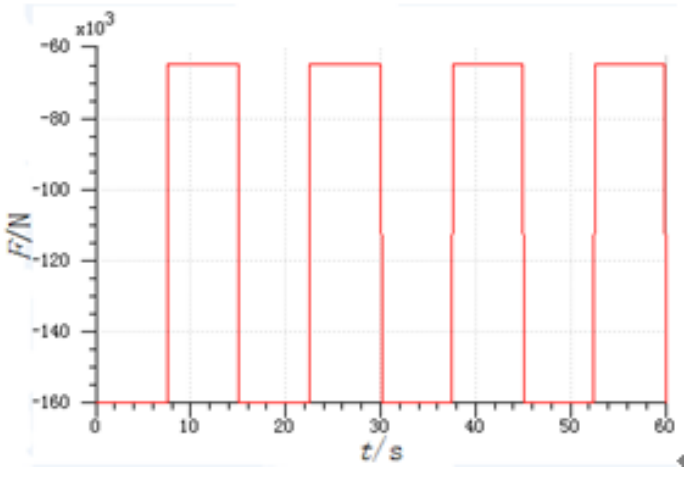

Figure 6: driving hydraulic cylinder 1 load curve

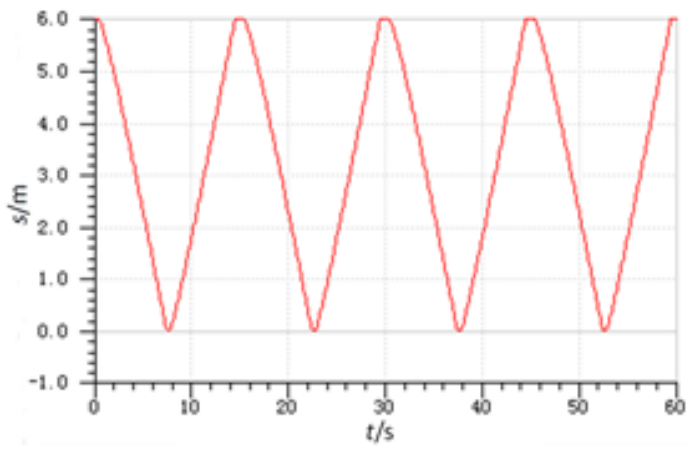

Figure 7 1: displacement curve of driving hydraulic cylind-

er

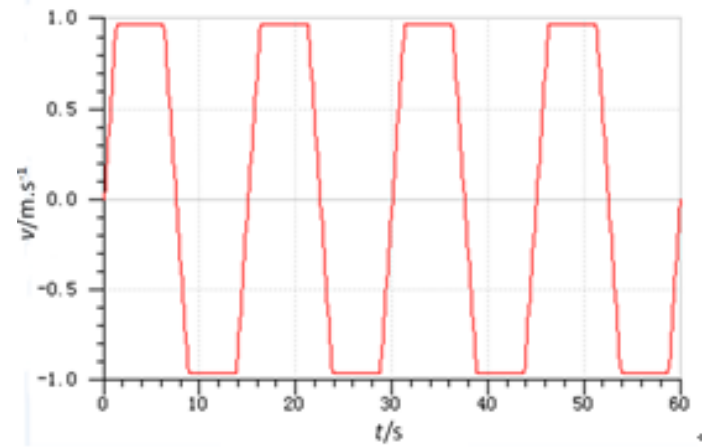

Figure 8: driving hydraulic cylinder 1 speed curve

Driving hydraulic cylinder 2 with the s-ame driving hydraulic cylinder 1 moveme-nt, in the opposite direction.According to the analysis results, double-well mutual ba-lance double-well oil hydraulic pumping unit of AMESim modeldriven hydraulic cylinders 1 and 2 of the displacement cur-ve and velocity curve are in conformity with the design curve (figure 4).Combine-d with the stroke, the design of the hydra-ulicpumping unit a time cycle of $12 \mathrm{~m}$, o-n the trip $6 \mathrm{~m}$, lower stroke $6 \mathrm{~m}$.Acceleration period and reduction period of time areused in 1.25 Seconds, deceleration distance of $0.6 \mathrm{~m}$; upper and lower stroke uniform movement period time of 5 seconds, unifor-m motion distance of $4.8 \mathrm{~m}$. The design ofthe hydraulic pumping unit has a longeruniform motion stage, variable motion stage only the total stroke travel $1 / 5$. Longer uniform motion stage of the unit with sta-ble operation, reduced the rod string and liquid column suffered shock loads and in-ertia loads.

The same specifications of the beam pu-mping unit to achieve maximum acceleration $0.9 \mathrm{~m} / \mathrm{s}^{2}$ and acceleration values have been changed, the maximum speed of $1.3 \mathrm{~m} / \mathrm{s}$ ${ }^{[5]}$.The same specifications LDCJ16-6type chain pumping unit calculated maxi-mum acceleration $1.85 \mathrm{~m} / \mathrm{s}^{2}$, the maximum speed of $0.8 \mathrm{~m} / \mathrm{s}^{[6]}$.Designed a double-we-llmutual balance hydraulic pumping unit with respect to the beam pumping unit an-d chain pumping unit has a minimumandstable acceleration and a suitable speed.I-n the pump suction process, changes in a-cceleration and greater acceleration is not good for the suction pump, and when the oilstability absorption stability, greater op-erating speed can increase the value of theoil pump speed.Therefore, this paper desi-gneda double-well mutual balance hydraulic pumping unit in terms of stability and change in acceleration rate advantage overthe same type of beam pumping unit andchain pumping unit.

\section{Conclusion}

This paper designs a kind of double-we-ll balanced hydraulic pumping unit, can re-alize double production at the same time compatible with single well oil production. The hydraulic pumping unit adopts the hy-draulic cylinder reciprocating drive rod, ea-sy to realize long stroke pumping unit re-quirements; double oil well production w-hen two differential pumping Wells, the bal-ancing oil cylinder stroke up and down;a-ccumulatorbalance when single oil well production accumulator up and down stroke, facilitate the well maintenance.AMES-im software using the hydraulic system si-mulation resulting motion characteristic curve is consistent with the design requirements.The simulation results show that the designed double-well mutual balancing hy-draulic pumping unit has a longer uniformmotion stage and a shorter variable motionstage, its acceleration is less than the same size of the beam pumping unit and cha-in drive pumping unit, improve the working conditions of pumping and extending the life of the pumping unit and its comp-onents.

\section{References}

[1] Bo Tao. The Development and State of Art of the Hydraulic Pumping Unit in China [J].Drilling \& Production Technology, 2002, 25(02): 68-70.

[2] Zhou Cheng.Development of Electro Hydraulic Proportional Lifting System of Rod Pump Simulation Test Device [D]. Zhe-ngjiang University, 2010.

[3] Zhang Xian-yu, Chen Xiao-hu, He Qingi-fei. Modeling and Simulation for Faultof Hydraulic Actuator Based on AMESim [J]. Hydraulics Pneumatics \& Seals, 2011, (10): 26-28.

[4] Jin Sheng-qiu, Cheng Kai, Wang Peng-yu. Analysis and Improving the Structure of Synchronization Valve Basedon AMESim[J]. Chinese Hydraulics \& Pneumatics, 2009, (09): 64-68.

[5] Xiong Da-jun, Liu Qiao-lin, Xu Zheng-guo. A Compound Balancing Pumping Unit with Phased Walking Beam and Phased Crank [J]. Petroleum Machinery, 2002, 30(07): 27-28.

[6] Ren Hongwei, Liu Yan-chong, Shi Yong-jun. Structure Design of Long-Stroke Chain-Type Pumping Unit with Axis Reversing [J]. Oil Field Equipment, 2009, 38(09): 39-41. 


\section{Author Profile}

Zhong Gongxiang (1962-), male, Sichuan Province, Chengdu city, sichuan province, Master, is mainlyengaged in petroleum mechanical engineering research and teaching. Address: (610 500) Xindu district of chengdu in sichuan province.

\section{Fund Project}

Ministry of Education Key Laboratory "Oil and gas equipment" (Southwest Petroleum University) funded projects (2014sts03). 